\title{
Determination of the level of separate rail failure using the indicator of their reliability
}

\author{
Anatolii Shtompel ${ }^{1}$, Oleksii Skoryk ${ }^{1}$, Vadym Novikov ${ }^{1}$, Yuliia Kravchenko ${ }^{2}$, and Yevhen \\ Korostelov $^{1 *}$ \\ ${ }^{1}$ Ukrainian State University of Railway Transport, Feierbakh Square 7, 61050, Kharkiv, Ukraine \\ ${ }^{2}$ Kharkiv Petro Vasylenko National Technical University of Agriculture, Department of Economics \\ and Marketing, Alchevskikh st., 44, 61002, Kharkov, Ukraine
}

\begin{abstract}
During the operation, the upper railway track structure constantly tends to age, which includes the increasing number of failures. This process is controlled by the track maintenance system, which provides for the current maintenance of the track in a certain railway section. As part of the current maintenance of the track, in particular, works are performed to eliminate defective elements of the upper railway track structure, which appeared during functioning of the track structure. The dependence of the operational cargo turnover on the amount of transported cargoes has been analyzed. It is directly related to the issues of organization of maintenance of the railway track structure taking into account the current track operation conditions. Regression analysis of the reported data allowed establishing a mathematical model of the dependence of the value of operational cargo turnover on the value of the transported cargo. The service life of rails (rail bars) in the track section has been established to be related to the indicator separate rail failure during the period of operation of the upper railway track structure by defects. The safety level of rails (rail bars) can be determined based on the value of this indicator.
\end{abstract}

\section{Introduction}

Appropriate mathematical models to predict the breakdown of elements of the upper railway track structure should be available (taking into account operational conditions of the railway section) to plan the rail repair during the current maintenance of the track. These models require the existence of an appropriate method for assessing the probability of failure of elements of the upper railway track structure, including rails.

The state of all elements of the upper railway track structure (within the life cycle of the upper railway track structure) should «ensure the safe and smooth movement of trains with the speeds established for this section» [1]. The technical condition of the track structure should be relevant to the level of the train traffic intensity, i.e., the railway track maintenance system should be susceptible to possible changes in the operational cargo

\footnotetext{
* Corresponding author: dek_str@ukr.net
} 
turnover. At the same time, these studies were conducted for the conditions of both main railways [2-5] and subways [6-7].

The issue of the numerical value of the indicator $m_{p}$ - separate rail failure (during the period of operation of the upper railway track structure) by defects has constantly been in the focus of the track studies [8-14].

\section{The basic part of the research}

One of the railway performance indicators is operational cargo turnover $Q_{\text {gr.oper. }}, \mathrm{mln}$. t. $\mathrm{km}$ gross. This indicator characterizes the amount of the train flow, which determines the power load on the track structure.

Thus, establishment of dependence $Q_{g r . o p e r}=f(t)$ for a certain period of time $(t-$ the current year of this period) is of practical importance for the track facilities and is directly related to the issues of organization of maintenance of the railway track structure.

The value of $Q_{\text {gr.oper }}$ is directly related to the volume of transported cargo $Q_{\text {cargo. }}$.

Using regression analysis of the corresponding reporting data, a mathematical model of dependence $Q_{\text {gr.oper. }}=f\left(Q_{\text {cargo }}\right)$, was established which has the following form:

$$
Q_{\text {gr.oper. }}=0.987 Q_{\text {cargo }}
$$

where the units of measurement of $Q_{\text {cargo }}$ and $Q_{\text {gr.oper }}$ are $\mathrm{mln} . \mathrm{t}$ and $\mathrm{mln}$. t.km gross, respectively.

The relevance of use of this mathematical model in confirmed with coefficient of correlation $r=0.998$ and coefficient of determination $r^{2}=0.995$.

In [3], the change of operational cargo turnover over the railway network in 2012-2016 was considered. It was found that the indicator $Q_{\text {gr.oper. }}$ varied linearly

$$
Q_{\text {gr.oper. }}=493.97-34.05 t
$$

Coefficient of correlation $r=0.967$ and coefficient of determination $r^{2}=0.935$.

Using the operational cargo turnover, average (over the railway network) traffic capacity of the main track can be determined

$$
\mathrm{C}_{\mathrm{aver} .}=Q_{\text {gr.oper. }} / L_{\text {main }}
$$

where $L_{\text {main }}$ - main track length (mln. t.km gross $/ \mathrm{km}$ per year).

I.e. for the specified period, dependence $\mathrm{C}_{\text {aver. }}=f(t)$ has the form as follows

$$
\mathrm{C}_{\text {aver. }}=16.7-0.66 t \text {, }
$$

coefficient of correlation $r=0.986$ and coefficient of determination $r^{2}=0.972$.

The service life of rails (rail bars) in a section is related to such an indicator as $m_{\mathrm{p}}-$ individual overage the operating life of the upper railway track structure by defects (rail failure during the period of operation of the upper railway track structure by defects (for the continuously welded rail track - the number of defective spots on a rail bar).

Some data on numerical value of this parameter (for new heat hardened rails R65) with the certain historical aspect are given in Table 1.

According to the analysis of data in Table 1, a unique estimate of the value of the indicator $m_{p}$ is unavailable. The lower limit of the indicator varies from three to ten rails per $1 \mathrm{~km}$ of track. Therefore, additional studies are required to define $m_{p}$ taking into account the current operational conditions of the track.

The value of the indicator $m_{p}$ is directly related to the reliability of the rails (rail bars), and therefore has a high practical value. 
Estimation of the reliability of rail bars of the continuously welded track during the operation involves the conditional division into segments each being $12.5 \mathrm{~m}$ long (such is the length of the rail insertion being welded into the bar during the final restoration of its integrity). In this case, rails of equalizing spans are not considered.

Table 1. Values of $m_{p}$

\begin{tabular}{|c|c|c|c|}
\hline \multirow{2}{*}{$№$} & \multirow{2}{*}{ Period, source } & Traffic capacity, & Value of the indicator \\
\cline { 4 - 4 } & 1960 -s [10] & mln. tkm gross $/ \mathrm{km}$ a year & $m_{p}, \mathrm{pcs} / \mathrm{km}$ \\
\hline 1 & & $25-50$ & 5 \\
\hline & & 25 & 6,53 \\
2 & $1970-\mathrm{s}[11]$ & 37.5 & 5,92 \\
& & 65 & 5,21 \\
\hline 3 & 1980 -s [12] & $50-80$ & 9 \\
\hline 4 & $2004[13]$ & 15 and more & 3 and more \\
\hline & & 30 & 8 \\
5 & $2008[14]$ & 50 & 6,5 \\
& & 80 & 5,6 \\
\hline 6 & $2010[8]$ & 15 and more & 10 and more \\
\hline 7 & $2014[9]$ & 15 and more & 3 and more \\
\hline
\end{tabular}

In [13], the dependence of the total separate failure $m_{p}$ of the heat hardened rails R65 (within a rail bar) on the total transported tonnage $\mathrm{T}$, million tons gross (for the sections with an average weighted axial load of $155 \mathrm{kN}$ and the train speed of $100 \mathrm{~km} / \mathrm{h}$ ) is given.

$$
m_{p}=0.56 \cdot 10^{-8} \mathrm{~T}^{3} .
$$

Probability of rail failures during the operation can be determined using the formula:

$$
F_{p}\left(t_{\mathrm{i}}\right)=m_{p}\left(t_{\mathrm{i}}\right) / N_{p},
$$

where $N_{p}$ - number of conditional $12.5 \mathrm{~m}$ long rails per $1 \mathrm{~km}$ track.

In this case this indicator is

$$
F_{p}\left(t_{\mathrm{i}}\right)=0.35 \cdot 10^{-10} \mathrm{~T}^{3} .
$$

Failure intensity for rails in the track section correlates with the dependence

$$
\lambda_{p}\left(t_{\mathrm{i}}\right)=m_{p}\left(t_{\mathrm{i}}\right) /\left[N_{\mathrm{p}}-m_{p}\left(t_{\mathrm{i}}\right)\right] \Delta \mathrm{T},
$$

where $\Delta \mathrm{T}$-transported tonnage in the period of time being considered.

Also, function $\lambda_{p}\left(t_{\mathrm{i}}\right)=f\left(\mathrm{~T}_{\mathrm{i}}\right)$ is described by the following mathematical model

$$
\lambda_{p}\left(t_{\mathrm{i}}\right)=0.35 \cdot 10^{-10} \mathrm{~T}^{4} .
$$

This model is the result of the corresponding processing of paired values $\lambda_{p}$ and $\mathrm{T}$ within interval $\mathrm{T}=50-750 \mathrm{mln}$. $\mathrm{t}$ gross.

Verification of the dependence (12) using the Fisher test confirmed the adequacy of the established model.

In Table 2, the results of calculation of some indicators are summarized.

Table 2. Results of calculation

\begin{tabular}{|c|c|c|c|c|c|c|c|c|}
\hline $\mathrm{T}, \mathrm{mln} . \mathrm{t}$ & 200 & 300 & 400 & 500 & 600 & 700 & 800 & 900 \\
\hline$m_{\mathrm{p}}, \mathrm{pcs} / \mathrm{km}$ & 0.045 & 0.151 & 0.358 & 0.700 & 1.210 & 1.921 & 2.867 & 4.586 \\
\hline$F_{p}\left(t_{\mathrm{i}}\right)$ & 0.0003 & 0.0010 & 0.0022 & 0.0044 & 0.0076 & 0.0120 & 0.0179 & 0.0255 \\
\hline $1-F_{p}\left(t_{\mathrm{i}}\right)$ & 0.9997 & 0.9980 & 0.9978 & 0.9956 & 0.9924 & 0.9880 & 0.9821 & 0.9745 \\
\hline
\end{tabular}


We can note as follows:

- after transporting $800 \mathrm{mln} . t$ gross, as reference value $T_{\text {ref }}$ for this upper railway track structure, appearance of three failed rails $\left(m_{p}=2.867 \mathrm{pcs} / \mathrm{km}\right)$ for $1 \mathrm{~km}$ of track with probability $F_{p}\left(t_{\mathrm{i}}\right)=0.0179$ should be expected, probability of failure-free operation of rail bars decreases from 1 to 0.9821 , i.e. approximately by $2 \%$;

- the results of calculations correlate with previous study [13], where a similar upper railway track structure was considered (bars of P65 rails, steel and concrete sleepers with KB fastening) and the probability of failure-free operation of rail bars (after transporting $600 \mathrm{mln}$. $\mathrm{t}$ gross) was determined being 0.9765 (in this case this indicator is 0.9924 , i.e. divergence is $1.6 \%$ ).

The latter confirms the relevance of use of the mathematical model (8) to determine the value of indicator $m_{p}$.

Thus, the value $m_{p}=3 \mathrm{pcs} / \mathrm{km}$ can be considered as the lower limit in the estimation of total separate rail failure in a certain track section.

Study [13] has established the admissible (provided rail operation is economically reasonable) level of the total separate rail failure $m_{p}$ for sections with different traffic capacity C (Table 3):

Table 3. Values of the indicator $m_{p}$ for sections with different traffic capacity C

\begin{tabular}{|c|c|c|}
\hline Indicator № & $\begin{array}{c}\text { Traffic capacity of the section } \mathrm{T}, \\
\text { mln. t-km gross/km per year }\end{array}$ & $m_{p}, \mathrm{pcs} . / \mathrm{km}$ \\
\hline 1 & 30 & 8 \\
\hline 2 & 50 & 6.5 \\
\hline 3 & 80 & 5.6 \\
\hline
\end{tabular}

The above data were processed to determine the corresponding dependence $m_{p}=f(\mathrm{C})$, which is described by the equation:

$$
m_{p}=0.0009 \mathrm{~T}^{2}-0.147 \mathrm{~T}+11.6
$$

Thus, the value of the indicator $m_{p}$ can vary from 3 to $11 \mathrm{pcs} / \mathrm{km}$ depending on parameter $C$, i.e. the track category.

The experience of the operation of the railway track suggests that the condition of the rail facilities in a certain section of the road is characterized by two main indicators:

- volume of the transported tonnage $\mathrm{T}$;

- total number of trail failure $m_{p}$.

In Table 4, recommendations concerning the indicator $m_{p}$ at the track section are given:

Table 4. Values of indicator $m_{p}$

\begin{tabular}{|c|c|c|c|}
\hline \multirow[t]{2}{*}{ Track category } & \multirow{2}{*}{$\begin{array}{l}\text { Transported tonnage } \\
\text { (service life, years), } \\
\% \text { of the reference one } \\
\text { (at least) }\end{array}$} & \multicolumn{2}{|c|}{$\begin{array}{l}\text { Total separate rail failure (number of } \\
\text { defect spots) after track laying (in } \\
\text { average at the section), pcs./km }\end{array}$} \\
\hline & & welded rail track & jointed track \\
\hline I-III & 100 & 3 and more & 5 and more \\
\hline IV & 100 & 4 and more & 6 and more \\
\hline $\mathrm{V}-\mathrm{VI}$ & 100 & 8 and more & 10 and more \\
\hline VII & 100 & \multicolumn{2}{|c|}{10 and more } \\
\hline
\end{tabular}

Thus, provided rail operation is economically reasonable, the level of the total separate rail failure $m_{p}$ for sections with different traffic capacity $C$ was determined. 


\section{Conclusion}

The performed regression analysis allowed determining the dependence of the operational cargo turnover on the volume of the transported cargo.

Also, determination of dependence $Q_{g r . o p e r}=f(t)$ for the certain period of time is of practical importance for the track facilities and is directly related to the issues of organization of maintenance of the railway track construction.

Average (for the railway network) traffic capacity of the main track was determined using the cargo turnover. However, it should be noted that parameter $\mathrm{C}_{\mathrm{aver}}$. changed not just in singe digit during the calculation period.

Dependence of rail failure intensity in a track section taking into consideration the current operation conditions were determined. For the considered operation conditions, after transporting $800 \mathrm{mln}$.t gross, appearance of three failed rails $\left(m_{p}=2.867 \mathrm{pcs} / \mathrm{km}\right)$ for 1 $\mathrm{km}$ of track with probability $F_{p}\left(t_{\mathrm{i}}\right)=0.0179$ should be expected, probability of failure-free operation of rail bars decreases by about $2 \%$;

The obtained results of calculations correlate with the finding of the previous studies for similar operation conditions of the railway track and the probability of the failure-free operation of rail bars (after transporting $600 \mathrm{mln}$. $\mathrm{t}$ gross) of 0.9765 was determined (in this case this indicator is 0.9924 , i.e. divergence is $1.6 \%$ ).

\section{References}

1. Rules of technical operation of the railways of Ukraine (Kyiv, 1995)

2. A. Stompel. Collection of scientific works on the materials of the international scientific and practical conference «Modern areas of theoretical and applied research». 27(1), 27-32. (2011)

3. A. Stompel Scientific view to the future. 6(2), 89-91. (2017)

4. A. Stompel, O. Skoryk, O. Ovchinnikov. Collection of scientific works of Sworld. 36(1), 64-69. (2014)

5. M. Kurgan, D. Kurgan, N. Khmelevskaya. Ukrainian Railway. 9-10(51-52), 14-21. (2017)

6. S. Voronin, O. Skoryk, Ye. Korostelov. Eastern-European Journal of Enterprise Technologies. 4(80). 11-17. (2016)

7. S. Voronin, O. Skoryk, V. Stefanov, D. Onopreychuk, Ye. Korostelov. MATEC Web of Conferences Transbud. 116, 03005. (2017)

8. E. Danilenko, M. Karpov, V. Yakovlev. Regulation on the system of conducting a track-and-field economy on the railways of Ukraine. (Kyiv, 2011)

9. Regulations on carrying out scheduled maintenance and repair works on the railways of Ukraine. (Kyiv, 2015)

10. P. Tsukanov, A. Zolotarsky. Railway Transport. 6, 27-33, (1961)

11. L. Krysanov, M. Klokov. Railway transport. Series «Traveling economy». 4, 18-26. (1986)

12. A. Bolotin, V. Shulga. Interuniversity Collected Works. 805, 94-97. (1989)

13. A. Shtompel, B. Nosenko, T. Stomp. A scientific glance into the future. 2(1), 72-75. (2016) 